\title{
CLODOVIS, BORNAYS E DENERS: UMA ANÁLISE DA “CRUZADA MORAL” CONTRA OS TREJEITOS E FACEIRICES NA TELEVISÃO BRASILEIRA DA DITADURA MILITAR
}

\author{
CLODOVIS, BORNAYS AND DENERS: AN ANALYSIS OF THE "MORAL \\ CRUSADE" AGAINST THE MANNERISMS AND COQUETTISHNESS IN \\ BRAZILIAN TELEVISION OF THE MILITARY DICTATORSHIP
}

\begin{abstract}
Resumo
A partir da noção de "guerras sexuais" de Rubin (1984), analiso neste artigo algumas tensões e disputas relacionadas à construção de significados sobre convenções de gênero e sexualidade em um contexto de florescimento de dois fenômenos televisivos no Brasil, os programas de auditório e as novelas. Duas trajetórias serão examinadas: a do costureiro Dener, cuja participação no Programa Flávio Cavalcanti gerou debates sobre o seu "modo de ser", e de Claudia Celeste, considerada a primeira "travesti" a fazer novela no Brasil. Busco analisar a relação instável desses sujeitos com esta tecnologia, a qual, no contexto da ditadura, contribuía para a produção de significados ambivalentes sobre essas performances: considerada como exótica, portanto estimulada pelo mercado de bens culturais, e, ao mesmo tempo, perigosa, em função dos supostos efeitos tóxicos à moral que poderia acarretar. Os dados que deram origem a este texto foram obtidos junto à fontes orais e material jornalístico.
\end{abstract}

Palavras-chave: Televisão. Sexualidades. Convenções Sociais. Ditadura. Travesti.

\begin{abstract}
From the notion of "sex wars" by Rubin (1984), I analyze in this article some tensions and disputes related to the construction of meanings about gender and sexuality conventions in a blossoming context of two television phenomena in Brazil, auditorium programs and novels. Two paths are examined: the Dener couturier, whose participation in the Flávio Cavalcanti program has generated debates on its "way of being", and Claudia Celeste, considered the first "travesti" to do soap opera in Brazil. I try to analyze the unstable relationship of these subjects with this technology, which, in the context of dictatorship, contributed to the production of ambivalent meanings of these performances: considered exotic, so stimulated by cultural goods market, and at the same time, dangerous, on the basis of alleged toxic effects to the moral that might entail. The data that gave rise to this text were obtained from oral sources and journalistic material.
\end{abstract}

Keywords: Television. Sexualities. Social Conventions. Dictatorship. Travesti.

\section{Thiago Barcelos Soliva}

Professor Assistente do Centro de Ciências da Saúde, Universidade Federal do Recôncavo da Bahia.

E-mail: thiagosoliva@ufrb.edu.br 


\section{Introdução}

Ao analisar a dimensão política da sexualidade, Gayle Rubin (1984) chama a atenção para o peso simbólico que alguns "valores sexuais" e "condutas eróticas" exercem em determinados contextos de grande estresse social. Em Thinking Sex: notes for a radical theory of politics os sexuality, a autora focaliza esses processos sociais nos quais a sexualidade é convertida em objeto de contestação e sua dimensão política é mais nitidamente delineada. A noção de "cruzada moral" constitui, assim, um recurso analítico adotado pela autora para capturar as diferentes articulações entre os dispositivos discursivos e suas implicações nas formas de regulação das sexualidades. Ao examinar a exacerbação das ansiedades relacionadas à sexualidade em dois espaços-tempo específicos - a Inglaterra e os Estados Unidos, do final do século XX, e os Estados Unidos, da década de 1950 -, Rubin (1984) oferece um rico panorama da forma como as "cruzadas morais" engendraram mudanças e ressignificações na organização da sexualidade. Muitas dessas mudanças, alerta Rubin (1984), são sentidas até hoje, como aquelas relacionadas à legislação, à educação das crianças e às práticas médicas.

Para Rubin (1984) os conflitos envolvendo a sexualidade se aproximam em seus sentidos e efeitos das disputas religiosas que ocorreram em séculos anteriores. O uso da expressão "cruzada" ganha a partir desse enfoque enorme sentido, uma vez que compartilha do mesmo significado de perseguição moral daqueles empreendimentos religiosos do passado, cujas iniciativas foram responsáveis por guerras sangrentas e perseguições violentas. O sentido de violência desses empreendimentos é capturado por Rubin (1984) na noção de "guerras sexuais". As "guerras sexuais" constituem assim mecanismos através dos quais ansiedades sociais são deslocadas, focalizando toda a intensidade emocional das sensibilidades coletivas em um alvo específico. Foi assim que, nos Estados Unidos da década de 1950, a imagem da "ameaça homossexual" foi convertida em objeto de um crescente medo público e seus personagens, o "ofensor sexual", passa a ser submetido a um exame minucioso (Rubin, 1984).

As consequências de tal "cruzada moral" impactaram diretamente as trajetórias de vida de sujeitos assimilados a essa imagem. Diferentes restrições foram impostas a esses sujeitos com o objetivo de exercer controle sobre seu comportamento e, mais que isso, eliminar "toda a homossexualidade da comunidade" (Rubin, 1984). Como afirma a autora, as "cruzadas anti-homossexuais" se alastraram por todo o país e constituíram o exemplo mais ricamente documentado da "repressão erótica" nos anos de 1950 nos Estados Unidos.

No Brasil, apesar de nunca ter se desenvolvido uma política sistemática de perseguição dos "desviantes sexuais", em expressão de Rubin (1984), como nos Estados Unidos foram produzidas estratégias similares de perseguição e, sobretudo, de mecanismos regulatórios cujo foco era reter o avanço da ameaça moralmente reprovável dessas práticas e sujeitos. Tais mecanismos estão profundamente associados à "cruzada moral" deflagrada pelas "famílias de bem" muitas das quais consagraram apoio direto ao Golpe Militar de 1964. Dadas essas considerações, este artigo se debruça sobre a articulação de dois processos sociais do Brasil contemporâneo: o crescimento da televisão como principal veículo de comunicação no contexto da ditadura e os mecanismos de regulação dos sujeitos considerados como "desviantes sexuais".

Dialogando diretamente com a noção de "guerras sexuais" de Rubin (1984), analiso neste artigo algumas tensões e disputas relacionadas à construção de significados sobre convenções de gênero e sexualidade em um contexto de florescimento de dois fenômenos televisivos no Brasil, os programas de auditório e as novelas. Duas trajetórias serão aqui focalizadas: a do costureiro Dener, cuja participação no Programa Flávio Cavalcanti gerou intensos debates sobre o seu "modo de ser", e de Claudia Celeste, considerada a primeira "travesti" a fazer novela no Brasil. Busco analisar a relação instável desses sujeitos com esta nova tecnologia, a qual, no contexto da ditadura, contribuía para a produção de significados ambivalentes sobre essas imagens: consideradas como exóticas, portanto estimuladas pelo mercado de bens culturais, e, ao mesmo tempo, perigosas, em função dos supostos efeitos tóxicos à moral que poderiam acarretar. 


\section{Metodologia}

Este trabalho foi produzido a partir dos relatos das trajetórias de vida de dois interlocutores privilegiados: Dener e Claudia Celeste. Para construção dessas trajetórias foram adotados diferentes investimentos quanto à coleta de dados. Duas biografias de Dener, uma escrita por ele mesmo, constituíram ponto de partida para a produção do material sobre a trajetória desse costureiro. A biografia escrita por Dener - Dener, o luxo - é um relato pessoal publicado por ele em 1972, no qual ele narra partes de sua vida, enfatizando as peripécias de seu trabalho como costureiro e sua relação com as elites. Já a biografia escrita pelo sociólogo Carlos Dória, em 1998, O Bordado da Fama, consiste em um trabalho rico em informações sobre diferentes episódios da vida do costureiro, principalmente a sua malsucedida relação com a ditadura.

Sobre Claudia Celeste, pude entrevistá-la em sua casa no bairro de Irajá, no subúrbio do Rio de Janeiro. $\mathrm{Na}$ ocasião, meu contato com ela foi facilitado por outro pesquisador que vinha interagindo com Claudia em função de outro interesse de pesquisa. Com essa mediação, ela aceitou me receber em sua casa, onde tivemos uma longa tarde de conversa. Ela também permitiu que visitasse o seu escritório onde reunia em muitas pastas recortes de jornais e fotografias sobre a sua carreira. Com sua autorização, fotografei esse material. Tive outros contatos com Claudia por telefone, através do qual tirava dúvidas sobre sua carreira.

Além dos recursos acima descritos, reuni dados sobre os dois em diferentes veículos de comunicação, como O Globo, Folha de S. Paulo, Jornal de Minas, Estado de Minas, Amiga, Gazeta de Notícias, Veja e O Cruzeiro. O acervo desses dois primeiros jornais está digitalizado em sites mantidos pelos próprios veículos de comunicação. A disposição desse recurso facilitou o trabalho de coleta de dados. Assinei o jornal $O$ Globo, sendo possível fazer as pesquisas no meu computador pessoal, as quais são facilitadas em razão dos mecanismos de buscas dispostos eletronicamente no site dedicado a esse propósito e mantido pelo jornal. O mesmo mecanismo também é mantido pela equipe do veículo Folha de S. Paulo, que vasculhei nos computadores da Biblioteca Nacional, onde pode ser usado gratuitamente. Os jornais mineiros que registraram os episódios polêmicos envolvendo Dener foram a mim confiados por outra pesquisadora cujos interesses de pesquisa são relacionados à ditadura. Este acervo foi reunido pelo professor Luiz Morando.

O uso das trajetórias, para esse propósito, conduz a algumas questões que merecem ser ressaltadas neste artigo. Bourdieu (1998), ao se debruçar sobre o tema, destaca os riscos a que os pesquisadores estão expostos de se construir trajetórias cujo efeito é a sensação de se relacionar com relatos de vidas lineares. Como observa o autor:

Tentar compreender uma vida como
uma série única e por si suficiente de
acontecimentos sucessivos, sem outro
vínculo que não a associação a um "sujeito"
cuja constância não é senão aquela de um
nome próprio, é quase tão absurdo quanto
tentar explicar a razão de um trajeto no
metrô sem levar em conta a estrutura da
rede, isto é, a matriz das relações objetivas
entre as diferentes estações (Bourdieu,
1998: 189-190).

A "ilusão biográfica" de que fala o autor reduz as trajetórias a narrativas totalizadoras, desconsiderando as 'colocações' e 'deslocamentos' possíveis que se relacionam às mesmas. Ao chamar a atenção sobre essas questões, Bourdieu (1998) alerta para a necessidade de se ficar atento para as tensões existentes no fluxo de vida, ou seja, os trânsitos entre o vivido e o desejado, peças fundamentais na construção dos projetos que dão contornos à vida dos indivíduos.

Outra dimensão significativa que se relaciona aos trabalhos que se utilizam das trajetórias de vida é a questão da memória. Essa discussão está intimamente ligada aos escritos de Maurice Halbwachs. Para Halbwachs (2006), a memória não deve ser percebida apenas como um produto das consciências individuais, mas, principalmente, como um fenômeno coletivo e social. Ao atribuir uma dimensão social à memória, Halbwachs a submete às contingências sociais - às flutuações, mudanças e transformações que organizam a vida social.

A partir das ideias do citado autor, Pollack (1989) irá chamar a atenção para a forma como a memória pode ser um componente importante para a coesão e a delimitação de fronteiras entre diferentes grupos sociais. Esse processo só pode se estabelecer a partir de um trabalho de "enquadramento" através do qual determinados elementos 
da história são selecionados e legitimados para poder representar a história de um dado grupo social. Essas ideias permitem perceber a memória como um efeito de seleção operada por hierarquias de prestígio. A memória não pode ser entendida como um processo biológico, mas social e situacional. Ela é organizada por escolhas conscientes e inconscientes, respeitando uma ordem social. Dialogando com essas ideias, este artigo não pretende entender essas trajetórias como totalidades lineares, mas em suas relações com contextos, agentes e, principalmente, com as relações de poder a que estão submetidas.

\section{Dener é um luxo! Programas de auditório, ditadura e sexualidades}

Fry (1982), ao analisar o Caso Febrônio, evidenciou o papel didático da imprensa em converter os "loucos morais", constantes na literatura médica, em "monstros" dos jornais diários (Fry, 1982). Tal processo de construção de "monstros" vai ser responsável por produzir uma percepção estereotipada das sexualidades não normativas, associada à inversão e assimilada ao crime e à loucura. Com a emergência de uma nova "tecnologia do olho" (Brah, 2006), a televisão, o papel didático dos veículos de comunicação ganha contornos ainda mais expressivos, convertendo esses estereótipos em mercadorias culturais. Se por um lado esses corpos eram tomados como perigosos pela ditadura atenda às agendas moralistas; por outro lado, tais estereótipos referidos a sexualidades e performances de gênero não convencionais foram constitutivos de um mercado de bens culturais e de entretenimento no Brasil, como pode ser percebido no sucesso das apresentações dos chamados "transformistas", como Erick Barreto, em programas de calouros de grande adesão popular, como os programas de auditório. Foi a partir desse movimento pendular, entre a proibição e ofreak show, que essas performances passaram a ser consumidas pelos lares brasileiros. A reflexão sobre esse movimento pendular é um exercício importante para compreender a inscrição das sexualidades não normativas no cotidiano brasileiro.

Contudo, cabe antes uma reflexão sobre a ideia de freak show e o que ele representa na construção de uma espetacular exibição dos chamados "anormais", assumida pela cultura de massas no Brasil e em outros países, sobretudo os Estados Unidos (Leite Júnior, 2006). Leite Júnior (2006), em seu trabalho sobre a pornografia "bizarra", se debruçou sobre as origens dos freak shows e o processo de construção da noção de freak, ressignificada pelo mercado de cultura de massas. Para o autor, os freaks podem ser compreendidos como aqueles indivíduos cuja existência encontra-se mediada entre os monstros da cultura popular e os doentes teratológicos, "descobertas" da ciência erudita. É nos freak shows que são apresentadas variedades de tipos considerados bizarros, característica quase sempre reputada a alguma anomalia corporal ou a alguma capacidade extraordinária dos corpos, quase não humana. Apesar de serem populares em várias partes da Europa, legados do contexto medieval, foi nos Estados Unidos, afirma Leite Júnior (2006), que esse tipo de exibição ganhou forte impulso, sobretudo na virada do século XIX, indo até a década de 1960 e oferecendo as bases para aquilo que o autor chama de "cultura da anormalidade".

Parece, contudo, que a representação como freak desses personagens na televisão tenha gerado mais curiosidade do que repulsa, tendo em vista o esforço televisivo em preencher seus programas de sujeitos que encarnavam estereótipos relacionados às sexualidades não normativas. A construção de imagens relacionadas à noção de freak ligada a essas pessoas, item da cultura de massas, tal como sugere Leite Júnior (2006), produziu muita fascinação sobre as mesmas. Tais imagens foram levadas ao interior das "casas de respeito", que tratava de adotá-las como mercadorias culturais.

A proibição foi certamente a primeira relação instituída entre as sexualidades não normativas e a televisão. O dramático desfecho do costureiro Dener no Programa Flávio Cavalcanti foi um episódio emblemático para se compreender a dinâmica dessas interdições e os interesses conectados a esta. O programa ficou conhecido nacionalmente pela irreverência de seu apresentador, o jornalista Flávio Cavalcanti. Iniciando a sua carreira em 1954, na rádio Mayrink Veiga, Cavalcanti passou pela Rádio Nacional e, logo depois, pela TV Rio. Na década de 1970, ele começou a apresentar na TV Tupi carioca o Programa Flávio Cavalcanti, uma exibição de variedades que ia ao ar aos domingos, às 20 horas. $\mathrm{O}$ show se tornou líder de audiência, sendo o primeiro desse formato a ser exibido via Embratel para todo o Brasil. 
A audiência se sustentava pela ousadia do seu apresentador, que ficou conhecido pelas entrevistas polêmicas consideradas nocivas às convenções morais da época. Foi Flávio Cavalcanti que instituiu o júri nos programas de auditório, um conjunto de pessoas formado por personalidades que eram consultadas sobre um dado tema. Esse tipo de formato - baseado na espontaneidade da resposta - gerou muitos problemas ao programa e ao seu apresentador em função da censura aos meios de comunicação operada em tempos de ditadura. Um dos mais famosos episódios foi reputado à presença da atriz Leila Diniz em seu júri. Considerada por demais transgressora, Leila chegou a sair disfarçada em uma das gravações quando a Polícia Federal apareceu ao estúdio para levá-la presa.

Não somente Leila Diniz foi perseguida e teve a sua imagem cortada do programa: a presença de Dener era entendida como perigosa às noções correntes de moral e bons costumes. Sua atuação no júri tornou-se ainda mais nociva à medida que a audiência crescia - cada vez mais interessada nas opiniões do estilista sobre os calouros que se apresentavam no palco do programa. Os bordões “É um luuuxo!”, “É um liiixo!” e “É uma glóóória!” se constituíam como hinos que seduziam uma plateia que via em Dener uma celebridade.

A carreira de Dener como estilista profissional se iniciou aos treze anos de idade quando foi convidado a ingressar como desenhista no ateliê da Casa Canadá, conhecido estabelecimento de moda no Rio de Janeiro, responsável por vestir as "mulheres da sociedade" na década de 1950. A trajetória de vida de Dener foi profundamente transformada quando ele passou a ser o estilista oficial da primeira-dama, dona Maria Teresa Goulart, esposa do então presidente João Goulart. Dener soube usar muito bem a projeção da primeira-dama a seu favor. Apesar de sua notoriedade nas elites paulistanas, foi sua presença destacada no Programa Flávio Cavalcanti que lhe proporcionou reconhecimento público imediato.

Para Dória (1998), o Programa Flávio Cavalcanti produziu nos seus jurados personagens - etiquetas - que seriam reproduzidos em outros programas com o mesmo formato, como a Buzina do Chacrinha. Essas etiquetas serviam como referências acerca do comportamento dessas personalidades - o "bonzinho", o "exibido", o "malvado", etc. Simultaneamente, o formato ao vivo oferecia uma oportunidade para essas pessoas falarem abertamente, sem censura, sobre diferentes temas, muitos dos quais proibidos pelos órgãos de repressão. Aparentemente, Dener ameaçava a censura não por suas opiniões nada ortodoxas, tais como as de Leila Diniz acerca da sexualidade das mulheres, mas antes pelo que representava. Seus trejeitos evidenciavam "uma ausência de virilidade" que começava a incomodar os censores. Esse incômodo foi incentivado por correspondências de pessoas comuns que exigiam que o estilista fosse retirado da televisão.

Entretanto, o sucesso de Dener na televisão foi incontestável. Evidentemente, esse sucesso estava associado às transformações pelas quais passaram a televisão no início da década de 1970, tal como a instituição da TV em cores e a busca por altos índices de audiência, que fizeram com que cada vez mais pessoas famosas, em diferentes ramos da sociedade, fossem convidadas a aparecer no vídeo. Após estrear no Programa Flávio Cavalcanti, o estilista foi convidado pela TV Itacolomi, de Belo Horizonte, para ser o apresentador de um programa de variedades, o primeiro em cores da televisão mineira, a ser reproduzido pela TV Tupi pelo resto do país (conforme edição do Estado de Minas, de 13 de abril de 1972). A TV Bandeirantes, de São Paulo, também lhe fez uma proposta, um programa de duração diária de dez minutos - Repórter indiscreto - no qual opinaria sobre moda, costumes, comportamento, etc. Ambas as emissoras só destacaram uma exigência: que Dener reproduzisse nos novos programas o ar afetado que lhe era característico no Programa Flávio Cavalcanti (Dória, 1998).

O desfecho não foi tão bem-sucedido como foi lucrativo. Um grupo de jornalistas de São Paulo logo se manifestou contrário ao Repórter indiscreto, alegando "total falta de masculinidade", e ainda acusaram Dener de não possuir registro profissional (Dória, 1998). Em Minas Gerais, a TV Itacolomi, que começou a transmitir Dener é um luxo, se viu impelida por entidades femininas do estado, sobretudo a Liga das Senhoras Católicas, a cancelar o programa, apesar dos índices de audiência terem alcançado picos na sua primeira e última apresentação. A essas senhoras juntou-se o comissário de menores de Belo Horizonte, Anael Pereira, o qual alertava para os riscos que os jovens corriam se o programa fosse mantido no ar. $\mathrm{O}$ comissário requereu junto ao Juizado de Menores medida 
de censura contra as aparições de Dener em emissoras de televisão em Minas Gerais (conforme O Jornal de Minas, em 27 de abril de 1972). Nesse contexto nada favorável, a censura começou a agir, retirando não somente Dener, mas também outros que assim como ele eram considerados tóxicos aos costumes por sua performance caracterizada por uma "total falta de masculinidade".

Sugiro que Dener começou a representar um problema quando sua imagem fugiu ao controle, momento em que as diversidades de gênero e sexualidade passaram a transbordar, a partir da televisão, para outros setores da vida social, sobretudo aqueles dotados de grande prestígio, como a academia. Na edição da Folha de S. Paulo de 29 de abril de 1972, Dener recebeu críticas dos deputados da Assembleia Legislativa de Pernambuco em função de um convite feito pelos alunos do curso de jornalismo da Universidade Católica de Pernambuco para ser patrono dos formandos daquela turma. A matéria dá destaque à fala eloquente e apaixonada do deputado Severino Cavalcanti, da ARENA, no sentido de retirar da TV a figura de Dener e todos aqueles que se assemelhavam a ele em comportamento. O político ressalta o quão perigoso era aquela presença para preservação moral da sociedade. A fala foi aplaudida por outros colegas, como Monsenhor Ferreira Lima, João Guilherme de Pontes e Manoel Gilberto. O jornal reporta que Monsenhor Ferreira Lima teria recorrido ao ministro da Justiça para que este expulsasse tal presença da televisão.

Toda essa polêmica teria começado quando um dos professores da Universidade Católica de Pernambuco, Rafael de Meneses, renunciou à cátedra como forma de repúdio ao convite feito pelos alunos. Tal fato provocou o alarde dos parlamentares, sendo mencionado por Severino Cavalcanti na referida matéria d'A Folha. O professor reforçava, em seus argumentos para abandonar a cátedra, o desrespeito dos universitários que fizeram o convite pela universidade e pelo ensino superior lecionado naquele estado. De acordo com ele, "Dener é um criador de deformações em nossos costumes e exorta o homem brasileiro a uma atitude demissionária" (Dória, 1998: 139). $\mathrm{O}$ apelo ao ministro da Justiça surtiu o efeito esperado.

Ao analisar os episódios finais da vida de Oscar Wilde, Didier Eribon (2008) destaca os eventos que levaram Wilde a ser preso naquele início do século XX. Semelhante ao que ocorreu com Dener, Wilde teve a sua vida íntima devassada diante da alegada suspeita de "homossexualidade" que o levou aos tribunais. Os episódios que marcaram o processo e posterior condenação de Wilde suscitaram debates acirrados acerca da "homossexualidade" naquela sociedade. No Brasil, já na década de 1970, Dener sofreu a condenação simbólica por sua performance não conforme em relação às convenções de masculinidade vigentes. Sofreu o peso da injúria de ser assimilado à homossexualidade. Seguindo o raciocínio de Eribon (2003), para quem a morte de Wilde converteu-se em um momento de mudanças no "papel homossexual" naquele país, Dener de algum modo fez o mesmo. Sua audiência, o triunfo de sua performance na televisão, promoveu uma consciência coletiva sobre as diversidades de gênero e sexualidade e ainda uma consciência de si entre as pessoas que o viam como exemplo pedagógico. Como afirma Eribon (2008), "toda palavra contra a homossexualidade é, ao mesmo tempo, uma palavra sobre a homossexualidade" (Eribon, 2008: 181), assim essa palavra é encarada com inquietação por indivíduos que, através do caso Dener, ouviam falar de si e do seu "jeito de ser", rompendo o indizível de sua experiência.

Da mesma forma que Dener, Clóvis Bornay, Mauro Rosas, Clodovil e Rogéria foram proibidos de ter suas imagens vinculadas à televisão. Clodovil foi desligado do programa Hora da buzina e Clóvis Bornay, do Programa Sílvio Santos. Ao vetar a aparição dessas pessoas, os censores acreditavam na eliminação dos perigos associados ao estigma da efeminação, sobretudo pela suposta ameaça à juventude ${ }^{1}$. A censura tornara-se ainda mais severa a qualquer artista ou personalidade que, aparecendo na televisão, comunicasse exemplos considerados negativos ao espectador. $\mathrm{O}$ ministro das Comunicações, Hygino Corsetti, acreditava na existência de uma televisão cuja programação estivesse livre de demonstrações de alcoolismo, erotismo e, sobretudo, das inversões sexuais (conforme a revista Veja de 17 de maio de 1972). Dessas orientações compartilhavam os ministros da Educação, Jarbas Passarinho, e da Justiça, Alfredo Buzaid (Dória, 1998).

Dessas determinações resultaram iniciativas mais rígidas de controle da programação televisiva, as chamadas

\footnotetext{
1 Gayle Rubin (2011) tece comentários muito próximos sobre a suposta ameaça que a "homossexualidade" proporciona aos jovens quando se debruça sobre a sociedade norte-americana.
} 
Normas de Conduta da TV. Essas normas obrigavam os veículos a gravarem toda a sua programação, incluindo os programas de auditório, para submeterem à censura prévia. $\mathrm{O}$ vídeotape ${ }^{2}$ constitui a principal tecnologia de supervisão nesse período. Através dele era possível assistir previamente o conteúdo dos programas e retê-los antes de irem ao ar. Das transformações ocorridas nos programas de auditório, destacam-se as mudanças no Programa Flávio Cavalcanti, que saiu do ar no dia 11 de junho de 1972, retornando em 23 de agosto do mesmo ano totalmente reformulado, mais curto, atendendo às ideias do ministro das Comunicações. Já na rede Globo, dois programas sofreriam intervenção. O Programa Sílvio Santos passaria a ser mais curto, e o apresentador Chacrinha perderia um dos seus programas, possivelmente, afirmava a Veja, a Discoteca do Chacrinha, televisionado às quartas-feiras (Veja, 17 de maio de 1972). Também estavam fora os "tipos perigosos" da televisão brasileira.

A revista Veja, em sua edição 180, de 26 de abril de 1972, tratou de registrar os episódios das demissões desses "tipos sem masculinidade" nas emissoras brasileiras, em matéria intitulada Veto ao trejeito:

A guerra está declarada e já fez a primeira vítima: Clóvis Bornay atingido por um fulminante bilhetinho da direção da rede Globo e afastado do Programa Sílvio Santos, na mesma semana. A ordem, atendendo "sugestão" da censura, era apenas desarmá-lo dos "trejeitos e das faceirices", mas, como sem essas armas Bornay não tinha função no júri, a solução foi mandá-lo embora. E, agora, um cerrado bombardeio moralista visa a desalojar dos programas de auditório (onde se tornaram figuras obrigatórias ultimamente) todos os militantes dos "trejeitos" (Veja, 1972).

A matéria destacava ainda o "beco sem saída" em que essas pessoas eram colocadas, uma vez que o autopoliciamento dos "trejeitos" não era suficiente para mantê-los na televisão, já que eram os mesmos gestos que construíam o interesse da plateia sobre eles. A matéria diz que Dener tentava contornar a situação controlando mais

2 Quem se beneficiou com a proibição expressa dos mecanismos de censura aos "tipos efeminados" foi a Rede Globo, que fez o governo federal investir na compra de custosos equipamentos de gravação, os quais foram cedidos à emissora. o corpo e tecendo elogios ao $\mathrm{Mobral}^{3}$, mas não obteve êxito. Clóvis Bornay constituía um escândalo ainda maior, posto que costumava aparecer no Programa Sílvio Santos com salto alto, bolsa e peruca.

A TV Itacolomi, diante do novo cenário, logo desfez o contrato com Dener, assumindo os altos custos de tal feito. O episódio com as senhoras mineiras foi descrito por David Nasser, da revista O Cruzeiro, em matéria intitulada $O$ sexo dos anjos, na qual criticava o pendor dos mineiros por tudo aquilo que era sólido no que se relaciona à vida social. $\mathrm{O}$ assunto ganhou muita projeção, demandando de Nasser um outro artigo que ele intitulou de Go home, bicharada!, no qual debate, em forma de novela, a situação dos excluídos da tela naqueles episódios. Os personagens Clóvis Bornay, Clodovil e Dener estão comentando, na matéria, as suas exclusões do vídeo, evidenciando uma crítica ácida às atitudes da ditadura contra um tipo de comportamento que, querendo ou não, estava consolidado, ficando a cargo da "natureza de cada um", afirmava Nasser, revelar-se.

Se a censura de hábitos teme a nossa presença no vídeo e receia o nascimento de inúmeros clodovis, bornays e deners pela semeadura das micro-ondas, respeitemos o zelo da censura. Voltemos aos nossos ateliês, às nossas passarelas, aos nossos teatros, aos nossos livros, às nossas canções, e deixemos que a natureza de cada um se manifeste livremente, antes que exploda nas ruas, numa estúpida marcha de protesto da família, as tabuletas mandando voltar para casa a bicharada, entre a qual, diga-se de passagem, não me coloco (Nasser, 1972).

A crítica de Nasser não ficou solitária entre a imprensa brasileira do período. O humor foi uma linguagem corrente adotada pelos veículos de comunicação para noticiar os episódios das demissões dessas pessoas das emissoras de televisão. O Estado de Minas, em 27 de abril de 1972, noticiava que uma gripe apelidada "Dener" afligiu Fortaleza em decorrência do tempo frio que chegou à região. $\mathrm{O}$ jornal destacou que as crianças eram as maiores vítimas da gripe, que assolou a capital e o interior cearenses. Tal notícia evidencia a habilidade com que a cultura popular assimilou as informações produzidas pelo

3 Movimento Brasileiro de Alfabetização. Trata-se de um projeto social do governo militar brasileiro cujo objetivo era promover a alfabetização para indivíduos acima da idade escolar convencional. 
governo em relação a essa presença na TV. O cartum do então iniciante Nani, em $O$ Jornal de Minas de 05 de maio de 1972, mostra com muito humor a interrupção dos trabalhos de Clodovil de Dener na televisão. Fica evidente na charge o quanto os "trejeitos", materializados no "ui" emitido por um dos personagens, foram o principal responsável pelo violento pontapé, ao mesmo tempo súbito, que extirpou as imagens dessas personalidades da televisão brasileira.

As reações, contudo, não foram somente da imprensa especializada. O público, apaixonado pelos bordões e jeito de ser dessas personalidades, protagonizou tentativas de resistência às censuras dos gestores públicos. O Jornal de Minas, em 07 de maio de 1972, noticiou a organização de uma passeata por um grupo de jovens em frente ao Canal 4, em São Paulo, solicitando o retorno do estilista Dener às telas. De acordo com Marcos Souza Lima, repórter responsável pela matéria, os jovens confeccionaram faixas com os dizeres: "Nós somos do Bloco do Luxo, exigimos a volta de Denner" (O Jornal de Minas, 1972). O apresentador Chacrinha também chegou a se pronunciar contra o veto das autoridades, segundo ele, na época, "o povo está ávido de gargalhar, de brincar e eles proporcionam isso" (Veja, 1972).

O conjunto desses eventos mostra evidências da ainda pouco explorada relação entre sexualidades não normativas e ditadura. É possível perceber que essa conexão é cercada de silêncios que carecem de pesquisas mais intensas sobre o período. Rodrigues (2014), no artigo De Denner à Chrysóstomo, a repressão invisibilizada: as homossexualidades na ditadura (1972 a 1983), afirma que a repressão contra as "homossexualidades" pelo estado autoritário, apesar de não contar com um dispositivo jurídico específico, não deixou de ser intensa, atuando, sobretudo, na proibição desses indivíduos nos grandes veículos de comunicação e no controle exercido sobre os eventos de entretenimento envolvendo as "travestis".

Porém, ao contrário do que queriam os censores, as sexualidades não normativas já ocupavam a cena pública. Mais do que a afetação que animava a plateia dos auditórios, a presença desses homens nesses programas de grande popularidade implicava uma insurgência das sexualidades não normativas nos lares brasileiros, contribuindo para a construção de um "papel não heterossexual" na nossa sociedade. O público não apenas gostava dessa presença como exigia os trejeitos, gritinhos, bordões e afetações característicos de Dener, o que representava não apenas um risco à moral e aos bons costumes da "família brasileira", mas, sobretudo, à autoridade militar - cujo poder foi conquistado graças ao apoio desses setores mais conservadores da sociedade.

A performance desses indivíduos foi produzida a partir do contato com esse público. O que era considerado pior pelos militares, o público reproduzia, em seus bordões. Essa recepção da audiência encorajava uma aceitação parcial das sexualidades não normativas. Parcial no sentido de que essa visibilidade era produzida na chave do grotesco, provocando, simultaneamente, risos e estranhamento. Mesmo que aprisionada a estereótipos, essas "formas de vida" passam a fazer parte do cotidiano dos lares brasileiros. Visualizada por centenas de aparelhos de televisão, especialmente em horários familiares, como o domingo, aqueles seres que antes habitavam o carnaval passaram a integrar a regularidade da vida cotidiana, sendo capturados por sentidos associados ao excêntrico e ao exótico.

Não somente a proibição marcou a relação da televisão com essas novas "formas de vida". Os programas de auditório promoveram ainda uma verdadeira espetacularização das sexualidades não normativas através de estratégias que muito se assemelhavam aos freak shows, como ocorria na cobertura pelos jornais e revistas dos bailes dos teatros da região da Praça Tiradentes. Os programas Show de Calouros, do apresentador Sílvio Santos, e o famoso Clube do Bolinha, apresentado por Édson Cury (Bolinha), se destacaram por essa presença "excêntrica" que promovia sentidos em torno dessas existências, revelando personagens que se consolidaram na vida cotidiana dos brasileiros.

Dos programas que mais contribuíram para a promoção de imagens sobre as sexualidades não normativas, o Clube do Bolinha é o mais representativo. Capitaneado por Édson Cury, o Bolinha, esse show televisivo, através do seu quadro Eles e Elas, foi o responsável por produzir performances relacionadas à "bichice" que seriam consolidadas na memória coletiva dos brasileiros. Édson Cury começou a sua carreira como animador de um programa chamado Chuveiro Lorenzetti, no segundo canal da Tupi ${ }^{4}$. Tratava-se de um programa de

4A TV Tupi possuía dois canais. 
calouros, no qual os cantores desafinados eram parados de cantar com um banho de ducha. Ganhou fama como locutor de campo na rádio Excelsior. Começou a fazer o Clube do Bolinha em 1974, ficando até 1994, sendo considerado um dos programas-líderes da TV Bandeirantes.

Tamanha era a repercussão do quadro em nível nacional que se refletia na vida do seu apresentador. De acordo com ele, em entrevista ao programa Jô Soares, em 1997, esse quadro teria despertado para si uma "fama", a qual, segundo ele, era de "viado". Chegaram mesmo a produzir rumores de que estaria casado com Telma Lipp, famosa "travesti" que compunha o seu corpo de jurados. O caso ganhou projeção pública quando uma jornalista do veículo Notícias Populares teria investido na notícia de que Bolinha e Telma iriam se casar. Bolinha foi entrevistado por diferentes veículos, chegando a ser sabatinado publicamente na Rádio Capital, quando muitas ouvintes manifestaram sua condenação ao caso.

O Eles e Elas foi criado em 1979, diante de um clima de intensa repressão instituído pela ditadura. De acordo com Bolinha, para que o quadro fosse ao ar, ele não podia nomear as calouras com a categoria "travesti". Deveria apenas dizer o nome da concorrente, ficando ao público a compreensão do conteúdo das apresentações. A dinâmica do quadro consistia em um concurso no qual as competidoras se apresentavam no palco, geralmente dublando cantoras ou músicas famosas. Quando Bolinha começava a apresentar o Eles e Elas, a música-tema Calúnia (Telma eu não sou gay) ganhava o auditório, demarcando o campo simbólico sobre o qual as calouras se inseriam.

Coincidentemente, a Telma aclamada por Ney Matogrosso na música-tema tinha o mesmo nome da famosa Telma Lipp, a "travesti" que compunha o corpo de jurados do programa, com quem Bolinha, de acordo com a mídia, teria um "caso". Além dessa aproximação simbólica, a música é plena de outros simbolismos relacionados às sexualidades não normativas, começando com o título, Calúnia. A noção de calúnia se aproxima da ideia de injúria, com a qual Eribon (2008) analisa a construção da subjetividade das pessoas identificadas como "homossexuais". O fio condutor da canção é um pedido para reatar uma relação amorosa estremecida pela suposta "homossexualidade" do rapaz, ressaltando a redenção do ator de suas experiências passadas, assumidamente "homossexuais". O personagem da canção afirma serem calúnias as acusações de que não teria se redimido do comportamento considerado moralmente reprovável. Nesse pedido fica implícita a percepção da "homossexualidade" como, simultaneamente, vergonhosa e anormal.

O pedido para reatar a relação é acompanhado da certeza de uma redenção dos atos que ficaram no passado, reabilitando o personagem às convenções sociais associadas a estereótipos de gênero: bobes para ela, terno para ele, elementos formadores da felicidade do casal. O tom melancólico da música afirma ainda mais o seu potencial de deboche dessas convenções, uma vez que era o caluniado quem, narrando o seu drama, expunha o dilema da vida dupla vivida por muitos "homens homossexuais", muitos dos quais mantêm mulher e família associados a uma outra vida na qual se entregam ao deleite sexual com iguais. A injúria envolvendo "travestis" famosas, tais como Telma Lipp, foi recorrente na década de 1980, não apenas Bolinha fora envolvido nessa teia, mas também o cantor Erasmo Carlos. Tais processos de acusação revelam o suposto potencial contagioso que as sexualidades não normativas tendem a atrair para aqueles que ousam exibilas.

O Show de Calouros do apresentador Sílvio Santos foi outro exemplo de programa de auditório no qual as sexualidades não normativas ganhavam ares de "espetáculo de consumo" (McClintock, 2010). O Show de Calouros começou a ser televisionado em 1973 pelos veículos TV Record e TV Tupi, em São Paulo, e TVS, no Rio de Janeiro. Em 1981, com o início das atividades do Sistema Brasileiro de Televisão - SBT, o programa ganhou mais projeção, sendo a marca de Sílvio Santos. Neste momento, a bancada do júri começou a ser formada por outros artistas da emissora convocadas pelo "patrão". Foi ainda na década de 1980 que os chamados "transformistas" começaram a ser destaque no programa, aguçando a curiosidade popular a esse respeito. Sugiro que essa presença foi um dos motivos da manutenção da audiência e da longevidade desse programa no ar.

O Show de Calouros consistia em um concurso de variedades, no qual, os calouros apresentavam os seus prodígios no palco para concorrer a prêmios. Aquele que conseguisse ir para grande final - contabilizando cinco apresentações - se estabelecia como grande vencedor. No 
júri, nomes como Consuelo Leandro, Aracy de Almeida, Pedro de Lara, Elke Maravilha, entre outros, revelavam a sua opinião acerca das apresentações. Algumas dessas manifestações eram marcadas pelo deboche e pelo desdém ao personagem freak que se encontrava no palco. Eram várias as modalidades de participação, sobretudo dos chamados "transformistas", os quais se notabilizaram como principais atrações do Show de Calouros. Um desses "transformistas" que mais despertou a atenção do público foi Erick Barreto, que ficou conhecido por suas reproduções da performance de Carmem Miranda.

A percepção dessas formas de sexualidade como freak foi consolidada de forma ainda mais acabada nas transmissões do Baile Gala Gay, importante baile de carnaval dedicado às "bichas" e "bonecas" realizado no Scalla - famosa casa de shows do Rio de Janeiro. A entrada e saída das pessoas que o frequentavam se constituía em "espetáculo de consumo" (McClintock, 2010), onde o que estava sendo consumido era o excesso - homens vestidos de mulher, silicone, frescura, erotismo, etc. -, elementos que foram responsáveis por consolidar um imaginário coletivo sobre as sexualidades não normativas nos marcos do estranhamento e do estigma.

Aparentemente, a noção de "transformista" parece ter sido adotada pela linguagem televisiva como um recurso para não mencionar a expressão "travesti”. Interessante destacar que a linguagem grotesca dos programas de auditório autorizava a presença desses indivíduos que vivenciavam o feminino no registro da paródia, mas, ao mesmo tempo, a presença das "travestis", como Rogéria e Divina Valéria, era silenciosamente negligenciada. Na revista Amiga de dezembro de 1972, o apresentador Chacrinha chama a atenção para o sucesso de Rogéria, a quem chama de "nossa Rogéria", em sua tournée pelo exterior, lamentando os problemas enfrentados pelas emissoras com a censura quando resolviam trazê-la ao ar. Tal proibição parece estar circunscrita à televisão, quando considerado o alarde protagonizado pela imprensa na época de retorno dessas "travestis" de suas estadias pela Europa. Profissionais importantes de veículos de comunicação, tais como Nina Chaves e Ibrahim Sued, noticiaram com entusiasmo essa chegada, dedicando páginas inteiras de revistas e jornais para divulgar especificidades da vida dessas "travestis".

\section{A breve conquista do horário nobre}

Não foi somente nos programas de auditório que as sexualidades não normativas se converteriam em “espetáculo de consumo" (McClintock, 2010). As novelas foram ainda um palco de tensões referentes às diversidades de gênero e sexualidade que merece um exercício de reflexão. Diferentes trabalhos têm se debruçado sobre a presença de personagens não heterossexuais nas tramas brasileiras. Não busco aqui revisar essa literatura, tampouco compreender a forma como essas personagens são construídas no curso das tramas. Procuro, antes, através da trajetória de Claudia Celeste, a primeira "travesti" a fazer novela no Brasil ${ }^{5}$, compreender como a proibição marcou a sua experiência de vida, ao mesmo tempo que delineava um espaço restrito para essas pessoas.

Nascida em uma família do subúrbio carioca, Irajá, Claudia Celeste começa a ter contato com os espaços de sociabilidade "bichal" carioca através de um amigo, o Pereira, quando ainda era cabo do Exército Brasileiro. Esse primeiro contato foi feito através de suas idas às diferentes casas de santo frequentadas por Pereira na Baixada Fluminense e subúrbio do Rio de Janeiro. Com 19 anos, já fora do exército, Claudia decide abandonar os estudos para fazer um curso de maquiagem. Após esse curso, ela consegue um emprego em um salão em Copacabana, bairro da Zona Sul do Rio de Janeiro. Sua trajetória está diretamente relacionada à ascensão de algumas "travestis" que começam a ganhar projeção na década de 1970: muitas delas saíram do Brasil e regressaram logo em seguida aclamadas pela audiência popular, como foi o caso de Divina Valéria.

Eu estava trabalhando em um salão em Copacabana, Valéria volta para o Brasil. Já era famosa, já tinha saído daqui, foi para a Europa, voltou em 1972. Em 1972, ela voltou por cima, então foi um escândalo! Saiu na capa da Manchete [revista] vestida por Clodovil, Guilherme Guimarães -

5 Rogéria fez, ao longo da sua carreira, participações em diferentes novelas da TV Globo. Algumas de suas personagens ficaram famosas, como foi o caso da Ninete, em Tieta, de 1989 e Alzira Celeste, em Lado a Lado, de 2012. 
grandes costureiros, entendeu? De Paris e não sei o que... De Givenchy e não sei o que... E aquela bicha alta e coisa: Valter ou Valéria? [...] Aí eu estava trabalhando no salão, quando eu vejo aquela revista: Valter ou Valéria? Aquilo me intrigou, porque eu nunca tinha visto aquilo na minha vida, eu estava com 20 anos, mas naquela época a gente era inocente. [...] Aí quando eu vi aquela mulher belíssima, dizendo que era Valter Fernando Gonzalez, eu fiquei louca, fiquei nervosa, fiquei atacada - era aquilo que eu queria, que eu estava buscando e não sabia. Desde criança eu não ficava botando os batons de mamãe escondido no banheiro, botando toalha na cabeça para dizer que era mulher, brincava com as bonecas da minha irmã e não sei o que [...]. Quando eu vi a Valéria assumida, que chegou de Paris e dentro de um vestido que eu olhei aquele peito, como é que ela conseguiu aquilo? Aquelas reportagens enormes, comprei e li todas as reportagens e tudo. Ela no Teatro Princesa Isabel, ela ia fazer um show com Miéli, e aí montaram aquele show e tudo, e aí a primeira coisa que eu fiz: eu comprei ingresso para eu assistir. Eu queria assistir. Fui lá para trás assim para... nervosa para ninguém me ver, aquelas coisas toda. Então, quando eu vi a bicha, que abriu a cortina e ela começa a cantar e aquelas coisas. Que eu vi aquela mulher belíssima, sob aqueles holofotes, aquele glamour, aquela coisa toda - eu fiquei alucinada, eu falei: "Ah, não, é isso que eu quero para a minha vida!" Pronto, aí comecei (Claudia Celeste).

Divina Valéria aparece na narrativa de Claudia Celeste como um marco importante na descoberta de seus projetos de vida e construção de si. Ainda que tivesse percebido desde muito jovem que era muito feminina, Claudia não sabia nomear, tampouco o que fazer com essa feminilidade. O glamour manifestado pela imagem de Divina Valéria no palco se constituiu como uma referência pedagógica para Claudia. A diva encarnada por Divina Valéria encorajou Claudia a assumir definitivamente outros projetos de vida, ela começou então a se hormonizar e a dançar em diferentes boates da Zona Sul do Rio de Janeiro, abandonando o trabalho de cabeleireiro. Foram esses espaços que a levariam mais tarde para a televisão.

A primeira atuação de Claudia Celeste em uma novela foi em 1977, em Espelho Mágico. O contexto da trama era o próprio meio artístico, que servia de fio condutor para a personagem de Sonia Braga, a qual fazia de tudo para ser reconhecida como artista, não se furtando, inclusive, a praticar sexo com pessoas que a ajudassem nesse processo. Claudia já participava do bas-fond noturno carioca há algum tempo, dançando em boates e fazendo "shows de travesti" no Teatro Brigitte Blair quando foi surpreendida pelo convite feito pela equipe da novela.

Aí foram no Teatro da Brigitte Blair, que ela estava com uma peça de mulheres lá que tinha, que era com as chacretes na época, entendeu? E eu era uma das atrações também, Claudia Celeste. Não dizia a travesti Claudia Celeste, eu era apresentada Claudia Celeste, acabou, entendeu? Quem soubesse que eu era travesti, sabe, quem não sabe ficava por ali mesmo. Eu era um artista que estava em cena. Aí eles contrataram algumas cenas no teatro dela para levar para a novela. E numa dessas cenas, o diretor Daniel Filho, gostou do número que eu fazia, que era Big Spender, eu fazia um balé que eu cantava Big Spender: "Hey, big spender! Spend a little time with me...", trum na cadeira com umas perucas tudo Black Power coloridas, umas coisas assim de puta, com umas sainhas curta e tudo, balé de cadeira que tinha com as bailarinas. E aí ele gostou desse balé, e queria que fosse o número pra Sonia Braga entrar nesse balé, dentro do balé, e tal e coisa. E aí foi feita assim a cena com esse balé. E aí eu fui contratada também porque eu estava lá no meio disso. Ninguém estava sabendo de nada que eu era travesti. Não foi comentado. Daniel Filho nem imaginava. Ninguém imaginou nada! (Claudia Celeste)

De acordo com Claudia, ninguém suspeitou que ela era "travesti" até que um jornal de Copacabana, o qual, de acordo com ela, tinha uma coluna dedicada a temas de interesse das "bichas", fez uma nota, assinada por Glorinha Pereira, usando uma foto e noticiando a sua participação na novela. Instantaneamente, Claudia Celeste ficou conhecida pelo público mais amplo como a "travesti" que estava na novela. A Gazeta de Notícias de 07 de agosto de 1977 noticiou em letras garrafais Cláudia (ou melhor, Cláudio), o travesti que enganou todo mundo, e revelou aspectos da trajetória de vida de Claudia, como a sua precoce ingestão de hormônio, com 17 anos, e a afirmação de que ela não escondeu de ninguém sua real "condição de travesti". A matéria finalizava destacando a incerteza do futuro de Claudia na Rede Globo. Diante do 
falatório motivado pela aparição de Claudia na televisão, a direção da telenovela optou por retirá-la dos capítulos que tinha gravado, restando somente quatro capítulos que contaram com a sua presença.

Claudia afirma que foi por causa dos militares que a sua participação não teve continuidade na novela. Entretanto, de acordo com reportagem da Contigo, revista de amenidades especializada na vida de famosos, na época da novela Olho por Olho, foi Daniel Filho que teria feito um escândalo quando descobriu que Claudia era "travesti", antes mesmo de qualquer investida dos censores federais, impedindo imediatamente que as cenas que já tinham sido gravadas fossem ao ar. A reação de Daniel Filho tinha uma razão de ser, já que, de acordo com a Gazeta de Notícias, de 07 de agosto de 1977, havia uma proibição federal que impedia que "travestis" como Valéria e Rogéria aparecessem no programa Fantástico. Apesar de Claudia Celeste não ter um personagem considerado importante para o conjunto da trama, sua presença em si era considerada perigosa em função da conhecida proibição dessas pessoas na TV.

Mesmo tendo sido retirada da trama, a aparição pública em dimensões como aquela estimulou a carreira de Claudia, que começou a participar de outras produções, sobretudo em boates do Rio de Janeiro. Nessas apresentações, Claudia quase sempre chocava a plateia com um strip-tease cuja função era borrar definitivamente as convenções relacionadas a sexo e gênero, uma vez que a informação de Claudia ser uma "travesti" era acompanhada da retirada completa da roupa, deixando todos os presentes com a marca da dúvida.

Foi somente em 1988 que Claudia Celeste retornou ao ar, com a novela Olho por Olho da Rede Manchete. Essa novela fazia parte de um conjunto de mudanças operadas na grade de programação desta emissora. A grade de programação composta de programas de entrevista, documentários e jornalismo não conseguia competir com uma programação de feição mais popular, tal como a Globo e o SBT produziam. Diante desse contexto, a novela Olho por Olho buscou repetir o êxito de Corpo Santo e Carmem, lançamentos anteriores que combinavam elementos polêmicos em seus enredos, que iam desde a prostituição até a participação de seus personagens em religiões afro-brasileiras. Essa mistura de marginalidades parecia atrair o público, fazendo a Rede Manchete liderar a audiência em relação a sua concorrente no negócio das novelas, a Rede Globo (Francfort, 2008).

A dimensão policialesca não fugia ao enredo de Olho por Olho, que tinha como ponto alto da história a vingança de três irmãos que tiveram o pai assassinado. A exemplo de Corpo Santo, a dimensão marginal da cidade do Rio de Janeiro com seus "tipos humanos" e "zonas morais" constitui o pano de fundo para os dramas e histórias dos personagens. Foi nessa teia de relações morais que Dinorá foi concebida. A personagem Dinorá foi pensada para ser vivida por uma "travesti", admite Claudia. Os autores, José Louzeiro e Geraldo Carneiro, queriam oferecer autenticidade a este personagem, uma "travesti" que morava com Paula, prostituta interpretada por Beth Goulart. Claudia disse que para o personagem foram feitos vários testes, sem que tivesse sido escolhida a atriz. Aproveitando a sua expertise conquistada em sua outra experiência com novelas, Claudia fez um teste considerado adequado aos objetivos do papel de Dinorá.

Foram 157 capítulos dos quais Claudia Celeste participou profissionalmente como atriz do elenco fixo ao longo da trama, não apenas fazendo uma "ponta", ela ressalta. Além de atuar, Claudia prestava uma espécie de consultoria sobre o "mundo dos inferninhos" do Rio de Janeiro para os escritores da novela e para a atriz Beth Goulart. Mesmo tendo feito uma participação que pode ser considerada histórica como a primeira "travesti" a entrar no espaço mais cobiçado da televisão na época, as novelas, Claudia acredita que a projeção que sua personagem poderia ter conquistado foi prejudicada por dois motivos: 1) o fato de a novela não ter sido produzida pela Rede Globo, mas sim por uma emissora em processo de formação de público, como a Manchete; e 2) a intensa visibilidade dedicada a Roberta Close no período, a qual impedia que os refletores fossem virados para outro personagem com as mesmas características.

Ainda que a participação na novela seja vista como um evento importante na sua trajetória, Claudia afirma que essa participação teria limitado profundamente o seu "campo de possibilidades" como artista. Segundo ela, depois da experiência como Dinorá, todos passaram a vê-la como apenas uma "travesti", que teria vivido o seu próprio drama particular - enredado nas tramas da prostituição - na novela. Claudia conta que ficou desapontada com a falta de oportunidades que encontrou 
pela frente depois da novela, o que a levou para a Europa, como fez a geração anterior de "travestis", cujo exemplo mais consagrado foi Rogéria.

\section{Considerações finais}

Este artigo se ocupou dos mecanismos acionados pela ditadura militar brasileira para a regulação das sexualidades não convencionais a partir do contexto televisivo. Quando comecei a minha pesquisa de doutorado - cujo foco era compreender as estratégias de resistência relacionadas às sexualidades não convencionais -, me deparei com a difícil tarefa de reunir informações de sujeitos como Dener e Claudia Celeste. Fui construindo inferências a partir dessas dificuldades, as quais iam me conduzindo a importantes questões de pesquisa ainda pouco exploradas pelos estudiosos das sexualidades não normativas.

Tomando o exemplo das "cruzadas antihomossexuais" empreendidas nos Estados Unidos da década de 1950, Rubin (1984) oferece um repertório de situações significativas para se compreender a construção dos "desviantes sexuais" naquele contexto. Prisões, demissões compulsórias, ameaças e outras formas de violência faziam parte das "estratégias de guerra" que a sociedade norte-americana produzia contra a "ameaça homossexual”. No Brasil, apesar das instituições punitivas nunca terem sistematizado perseguições e "caças" a esses sujeitos, essas estratégias assumiram tons mais silenciosos, mas não menos impactantes.

O tom melancólico com que Claudia Celeste relembra o período em que esteve na televisão tem o poder de captar o impacto dessas "guerras" nas trajetórias de vida de sujeitos como ela. A impossibilidade de viver outras personagens que não ela mesma, a ausência de convites e a perda de expectativas fizeram Claudia decidir tentar uma carreira na Europa, reorganizando seus projetos de vida. Claudia abandona o Brasil magoada e certa de que seu futuro poderia ter sido diferente se seu talento fosse julgado antes do fato de ser "travesti".

Com Dener não foi muito diferente. Dória (2008), ao analisar os eventos que envolveram Dener, a televisão e a ditadura oferece uma imagem igualmente melancólica do costureiro às vésperas de sua morte, em 1978. O autor chama a atenção para a dedicação de Dener à televisão, deixando inclusive de trabalhar em seu ateliê em função dessa participação. Ao ser silenciado, Dener não conseguiria retornar ao ritmo de trabalho de outrora. Perdera também muitas clientes em função do tumultuado contexto a que foi exposto. Nesse ínterim, o uso descomedido de álcool foi convertido em refúgio. Todos esses fatos agravaram o seu estado já frágil de saúde, o que levou Dener a falecer vítima de cirrose hepática.

$\mathrm{O}$ exame das trajetórias (quase) invisíveis de Dener e Claudia Celeste aponta para um aspecto pouco problematizado pela análise de Rubin (1984), o apagamento. Este dispositivo talvez tenha sido uma das "estratégias de guerra" mais bem sucedidas contra as sexualidades não convencionais no Brasil. Espero que futuras pesquisas lancem luz sobre esses sujeitos apagados evidenciando assim as diferentes formas como a sociedade brasileira buscou regular essas sexualidades.

\section{Referências bibliográficas}

ABREU, Dener Pamplona de. (1972). Dener, o luxo. São Paulo: Laudes.

BOURDIEU, Pierre. (1996). “A ilusão biográfica”. In: AMADO, Janaína; FERREIRA, Marieta de Moraes (Org.). Usos e abusos da história oral. Rio de Janeiro: Editora da FGV.

BRAH, Avtar. (2006). "Diferença, diversidade, diferenciação", Cadernos Pagu, n. 26, p. 329-376, janjun.

DÓRIA, Carlos. (1998). Bordado da fama: uma biografia de Dener. São Paulo: Editora SENAC.

ERIBON, Didier. (2008). Reflexões sobre a questão gay. Bauru: Companhia de Freud.

FRANCFORT, Elmo. (2008). Rede Manchete. Aconteceu, virou história. São Paulo: Imprensa Oficial.

FRY, Peter. (1982). "Febrônio Índio do Brasil: onde cruzam a psiquiatria, a profecia, a homossexualidade e a lei”. In: Eulálio, Alexandre et al (Org.). Caminhos cruzados: Linguagem, Antropologia e Ciências Naturais. São Paulo: Brasiliense. 
HALBWACHS, Maurice. (2006). A memória coletiva. São Paulo: Centauro.

LEITE JÚNIOR, Jorge. (2006). Das maravilhas $e$ prodígios sexuais: a pornografia "bizarra" como entretenimento. São Paulo: Annablume.

MCCLINTOCK, Anne. (2010). Couro imperial: raça, gênero e sexualidade no embate imperial. Campinas: Editora da Unicamp.

POLLAK, Michael. (1989). "Memória, esquecimento, silêncio". Estudos Históricos, v.2, n.3, p. 03-15.

RODRIGUES, Rita de Cássia Colaço. (2014). "De Denner à Chrysóstomo, a repressão invisibilizada: as homossexualidades na ditadura (1972 a 1983)". In: GREEN, James; QUINALHA, Renan. (Org.). Ditadura e homossexualidades: repressão, resistência e a busca da verdade. São Carlos: Edufscar.

RUBIN, Gayle. (1984). "Thinking sex: notes for a radical theory of the politics of sexuality. In: Vance, Carole (Ed.). Pleasure and Danger: exploring female sexuality. Nova York: Routledge.

Recebido em: 22/04/2017.

Aceito: 18/06/2017. 